\title{
AVALIAÇÃO QUANTITATIVA E CRÍTICA DA PÓS-GRADUAÇÃO LATO SENSU DA UNIVERSIDADE FEDERAL DE GOIÁS, REGIONAL JATAÍ, DE 2002 A 2018
}

\author{
Adriana Luize Bocchi ${ }^{1}$ \\ Vera Lúcia Banys ${ }^{2}$ \\ Andréia Vitor Couto do $\mathrm{Amaral}^{3}$
}

\begin{abstract}
Resumo: Objetivou-se avaliar quantitativamente a pós-graduação Lato Sensu na Regional Jataí, de 2002 a 2018, mostrando o número de cursos ofertados, o número de egressos dos mesmos e a evolução da oferta dos cursos de especialização pela instituição. Foi realizada a análise retrospectiva crítica e censitária dos dados relativos à pós-graduação Lato Sensu da Regional Jataí do período de janeiro de 2002 a março de 2018, disponíveis no Sistema de Pós-graduação (SISPG) da Universidade Federal de Goiás (UFG). Os dados foram organizados utilizando-se o programa Excel 2013 da Microsoft ${ }^{\circledR}$, versão for Windows 10 , em tabelas que permitiram a avaliação descritiva dos mesmos. A primeira especialização ofertada na Regional Jataí foi a de Matemática, em 2002. Desde então, foram ofertados 21 cursos de especialização em várias áreas do conhecimento, bem como de residência multiprofissional, com a titulação de 294 profissionais nas diversas áreas do conhecimento. Pode-se concluir que, a Regional Jataí ofertou e tem ofertado pequeno número de cursos e turmas de Pósgraduação Lato Sensu, apresentando grande descontinuidade. Por isso, deve-se desenvolver um trabalho de estímulo a criação de novas turmas e cursos demandadas a partir de levantamentos realizados por área, na região, afim de garantir a continuidade dos mesmos uma vez que haverá suporte administrativo a partir da Secretaria Geral de Pós-graduação e há a garantia da contabilização da carga horária ministrada no Lato Sensu no relatório de atividades do professor.
\end{abstract}

Palavras-chave: Especialização. Residência multiprofissional. Residência uniprofissional.

\section{QUANTITATIVE AND CRITICAL EVALUATION OF THE POST-GRADUATION LATO SENSU OF UNIVERSIDADE FEDERAL DE GOIÁS, REGIONAL JATAÍ, FROM 2002 TO 2018}

\begin{abstract}
The objective with this study was to evaluate quantitatively the Lato Sensu postgraduate in Jataí Regional, from 2002 to 2018, showing the evolution of the number of courses offered as well as the number of graduated students. A retrospective study and census data evaluation of the Lato Sensu postgraduate of Jataí Regional was carried out from January 2002 to March 2018 using the Postgraduate System (SISPG) of Universidade Federal de Goiás. Data were organized using Microsoft ${ }^{\circledR}$ Excel 2013 program, version for Windows 10, in tables which allowed a descriptive evaluation of them. The first specialization offered in the Jataí Regional was Mathematics in 2002. Since then, 21 specialization courses have been offered in several areas of knowledge, as well as multiprofessional residency, resulting in the qualification of 294 professionals in various knowledge

\footnotetext{
${ }^{1}$ Professora da Zootecnia na Unidade Acadêmica Especial de Ciências Agrárias. Coordenadora de Pósgraduação Lato Sensu albocchi@ hotmail.com

${ }^{2}$ Professora de Forragicultura e Pastagens do Curso de Zootecnia da Unidade Acadêmica Especial de Ciências Agrárias - Coordenadora de Pós-graduação da Regional Jataí. verabanys@gmail.com

${ }^{3}$ Professora de Clínica de Pequenos Animais na Unidade Acadêmica Especial de Ciências Agrárias Coordenadora de Pós-graduação Stricto Sensu. andreiavcvet@ hotmail.com
} 


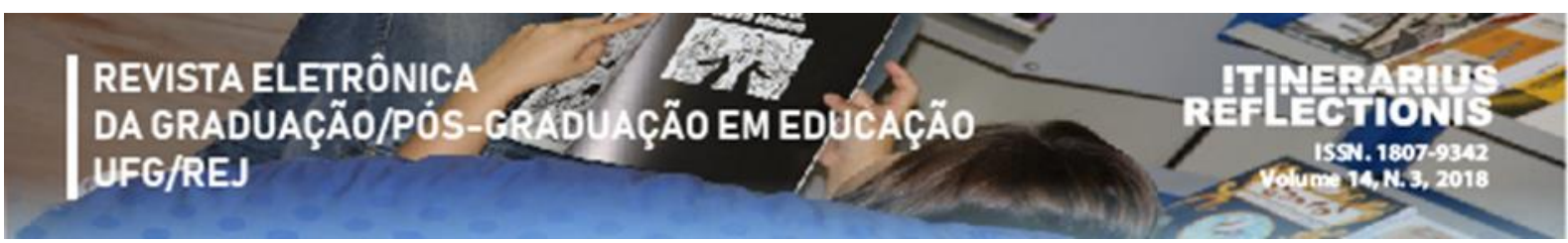

areas. It can be concluded that, the Regional Jataí offered and has offered a small number of courses and classes of Post-graduation Lato Sensu, presenting great discontinuity. Therefore, work should be done to stimulate the creation of new classes and courses demanded from surveys conducted by area in the region, in order to ensure their continuity, since there will be administrative support from the General Secretary of Post-graduation and there is the guarantee of Lato Sensu workload accounting in the report of teacher's activities.

Keywords: Specialization. Multiprofessional residence. Uniprofessional residence.

\section{INTRODUÇÃO}

De acordo com a Lei de Diretrizes e Bases da Educação Nacional (LDB n ${ }^{\circ}$ 9.394/1996) a educação tecnológica e profissional, no cumprimento dos objetivos da educação nacional, integra-se aos diferentes níveis e modalidades de educação e às dimensões do trabalho, da ciência e da tecnologia podendo ter, seus cursos, organizados por eixos tecnológicos, a possibilidade da construção de diferentes itinerários formativos, observadas as normas do sistema e nível de curso de pós-graduação compreendendo programas de mestrado e doutorado, cursos de especialização, aperfeiçoamento e outros, abertos a candidatos diplomados em cursos de graduação e que atendam às exigências das instituições de ensino.

Segundo o Parecer no 977/65, CESu, de 03 de dezembro de 1965, a distinção entre pós-graduação Stricto Sensu e Lato Sensu, cursos que se seguem à graduação, está no fato de que os cursos de especialização e aperfeiçoamento tem objetivo técnico profissional específico e não abrangem o campo total do saber em que se insere a especialidade. São destinados ao treinamento nas partes de que se compõe um ramo profissional ou científico e sua meta é o domínio científico e técnico de certa e limitada área do saber ou da profissão, para formar o profissional especializado.

Ainda de acordo com a Coordenação Geral de Legislação e Normas da Educação Superior, os cursos de Aperfeiçoamento visam à melhoria do desempenho e das competências anteriormente adquiridas numa determinada profissão, ficando a cargo da instituição de educação superior definir sua estrutura e especificidade, respeitada a carga horária total mínima de 180 horas (Parecer nº 977/65).

Enquanto que, segundo a Nota Técnica $\mathrm{n}^{\circ}$ 388/2013/CGLNRS/DPR/SERES/MEC, republicada em de 10 de abril de 2015, os cursos de Especialização, incluindo aqui aqueles designados como Master Business Administration (MBA), operam essencialmente no setor técnico-profissional visando promover o conhecimento especializado em um limitado e peculiar campo do saber e deve apresentar 


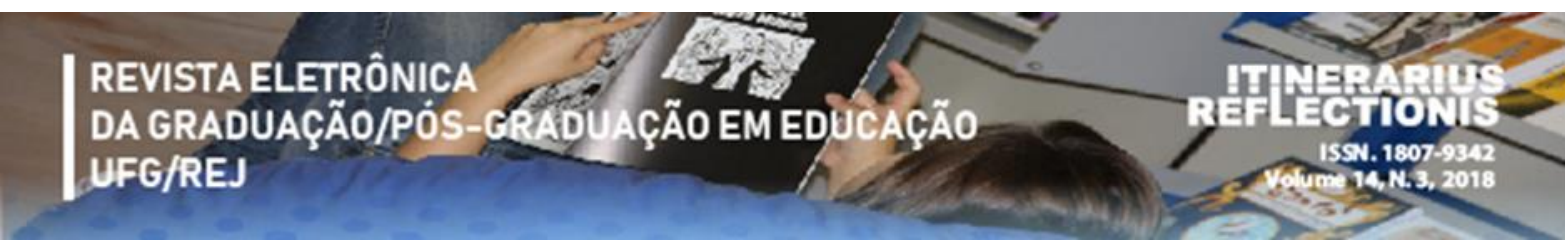

duração mínima de 360 horas em aulas, excluindo-se, portanto, o tempo de estudo e de elaboração do trabalho de conclusão do curso.

A importância dos cursos de pós-graduação Lato Sensu para o país é imensurável, bastando-se analisar a crescente necessidade de capacitação teórico-prática, ou mesmo a atualização, em qualquer modalidade profissional (FONSECA \& FONSECA, 2016). Assim, o papel da UFG, Regional Jataí, torna-se fundamental, por ser referência em educação e por estar inserida no Sudoeste goiano, região em ampla expansão agroindustrial e de grande representatividade em números populacionais.

De acordo com a RESOLUÇÃO - CEPEC N 1128 que aprova o Regulamento Geral dos Cursos de Pós-graduação Lato Sensu da UFG, os Cursos de Pós-graduação Lato Sensu da Universidade Federal de Goiás tem por finalidade a capacitação profissional e/ou acadêmica em áreas específicas e compreendem os cursos de especialização e os de residência médica, residência profissional e residência multiprofissional em saúde.

Devido a importância dos cursos de especialização na capacitação, universidades que abrangem diversas áreas de conhecimento como a UFG Regional Jataí apresentam a possibilidade de ofertar cursos de pós-graduação Lato Sensu para a cidade e região, se tornando um polo de conhecimento. Em função disso, se faz premente conhecer o histórico dos cursos ofertados como referencial das ações a serem tomadas para fortalecer, consolidar e ampliar a pós-graduação Lato Sensu na Regional

\section{OBJETIVO}

Objetiva-se com este estudo avaliar quantitativamente a pós-graduação Lato Sensu na Regional Jataí, desde a sua criação até a atualidade, mostrando o número de cursos ofertados, número de egressos dos mesmos e a evolução da oferta de cursos de especialização pela instituição, fazendo a avaliação crítica destes.

\section{METODOLOGIA}

Foi realizado o estudo retrospectivo e censitário dos dados relativos à pósgraduação Lato Sensu da Regional Jataí do período de janeiro de 2002 a março de 2018, disponíveis no sistema da pós-graduação (SISPG) da Universidade Federal de Goiás (UFG). 


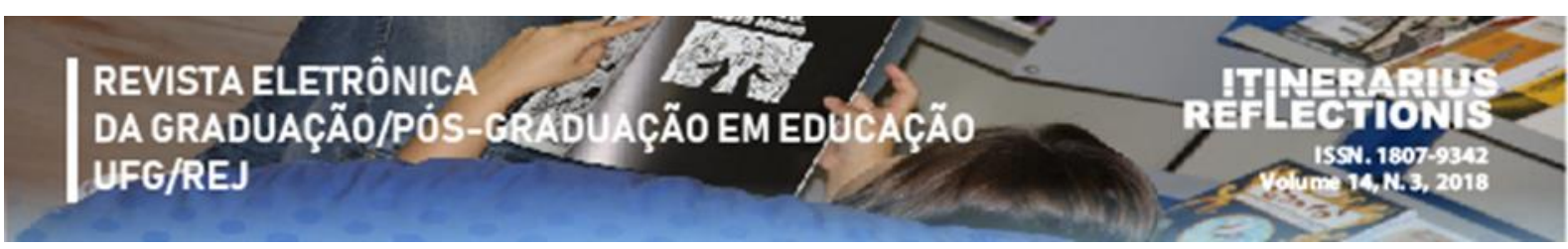

Os dados foram organizados utilizando-se o programa Excel 2013 da Microsoft $®$, versão for Windows 10, na forma de tabelas a partir das quais foram realizadas as avaliações críticas.

\section{RESULTADOS E DISCUSSÃO}

A primeira especialização ofertada na Regional Jataí foi a de Matemática, em 2002. Desde então, foram ofertados 21 cursos de especialização em várias áreas do conhecimento, bem como de residência multiprofissional.

Na Tabela 1 podem ser observados os cursos ofertados até março de 2018 na UFG, Regional Jataí, o número efetivo de cursos e o ano de início da primeira e finalização da última turma.

Tabela 1 - Cursos de pós-graduação Lato Sensu ofertados na Regional Jataí, UFG, no período de janeiro de 2002 a março de 2018, número de turmas, ano de início da primeira e de finalização (ou previsão de finalização) da última turma

\begin{tabular}{lccc}
\hline \multicolumn{1}{c}{ Curso } & No. de Turmas & Inicio & Fim \\
\hline Avaliação e Prescrição de Exercícios Físicos para & 1 & 2009 & 2010 \\
Populações Especiais & 1 & 2004 & 2005 \\
Biologia & 1 & 2004 & 2006 \\
Educação Física Escolar & 4 & 2004 & 2011 \\
Educação Infantil & 2 & 2015 & 2017 \\
Epidemiologia e Saúde & 1 & 2008 & 2010 \\
Gestão de Pessoas nas Organizações Públicas & 2 & 2011 & 2015 \\
História Cultural: Narrativas e Linguagens & 2 & 2010 & 2015 \\
Linguística Aplicada ao Ensino de Língua Materna e & 2 & 2006 & 2009 \\
Estrangeira (Inglês) & 1 & 2002 & 2003 \\
Literatura e Língua Portuguesa & 1 & 2010 & 2011 \\
Matemática & 1 & 2011 & 2013 \\
Matemática Aplicada & 1 & 2009 & 2010 \\
Matemática para Professores de Ensino Fundamental e & 2 & 2012 & 2016 \\
Médio & 1 & 2011 & 2013 \\
Meio Ambiente: Educação e Gestão Ambiental & 1 & 2015 & 2016 \\
Políticas, Gestão e Financiamento da Educação & 1 & 2012 & 2014 \\
Produção de Suinos & 1 & 2013 & 2015 \\
Produção Florestal & & 2013 & 2015 \\
Residência Médico Veterinária em Reprodução Animal & 1 & 2013 & 2015 \\
Residência Médico Veterinária em Clínica e Cirurgia de & 1 & 2012 & 2019 \\
Grandes Animais & 6 & & \\
Residência Médico Veterinária em Patologia Animal & & & \\
Residência Médico Veterinária em Patologia Clínica & & & \\
Residência Médico Veterinária em Clínica Médica, & & & \\
\hline
\end{tabular}


REVISTA ELETRÔNICA

DA GRADUAÇÃO/PÓS-CRADUA AÇÃO EM EDÜCACÇÃO

UFG/REJ

Clínica Cirúrgica e Anestesiologia de Animais de

Companhia

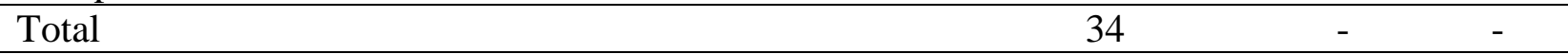

Fonte: SISPG (2018)

Observando os dados da Tabela 1, observa-se que a maioria dos cursos apresenta somente uma ou poucas turmas, finalizando em curto espaço de tempo. Fazendo um comparativo com os cursos de especialização ofertados pela UFG de Goiânia tem-se que, no primeiro semestre de 2017 foram ofertadas 28 turmas, no segundo semestre de 2017 seis turmas e no primeiro semestre de 2018 um total de 21 turmas de cursos em diversas áreas. Oito cursos ou $38 \%$ da oferta de cursos de 2018, não são novos cursos, mas sim novas turmas ofertadas, revelando a característica de continuidade dos cursos de especialização da Regional Goiânia (PRPG, 2018) o que pode ser devido a própria população da cidade que é de 1.466.105 habitantes ou 14,9\% maior que a de Jataí, de 98.128 (IBGE, 2017).

Da mesma forma, a Universidade de São Paulo (USP) ofereceu para o segundo semestre de 2018 um total de 22 cursos (USP, 2018). Entretanto, a USP trabalha com a distribuição de cursos de graduação por área entre seus Campi tendo, portanto, média de sete cursos por unidade e diferente da UFG que apresenta cursos de graduação dos vários campos do saber em todas as Regionais, que totalizam 93 e 25 cursos em Goiânia e Jataí, respectivamente. Com esse comparativo, nota-se que o quantitativo de cursos de pósgraduação Lato Sensu ofertados até o momento pela Regional Jataí é inexpressivo em relação às áreas e cursos de graduação existentes na mesma até por que, muitos cursos foram criados para atender à demanda específica e pontual de públicos específicos e previam apenas uma turma.

Durante o diagnóstico foi levantada a hipótese que o corpo docente efetivo seria pequeno, inviabilizando a dedicação aos cursos de especialização. Em levantamento realizado em 2015 a UFG de Goiânia contava com 15.962 alunos e 2.147 professores, numa relação alunos/professor de 7,4. Na UFG Regional Jataí no mesmo levantamento havia 3.100 alunos e 380 professores, numa relação de 8,1 alunos por professor (UFG, 2015), permitindo constatar que há possibilidade de maior parte da dedicação dos professores de Goiânia ser direcionada ao ensino da especialização.

Além disso, foi questionado junto à Coordenação de Pós-graduação e aos coordenadores dos cursos de especialização da UFG Regional Jataí quais seriam as 


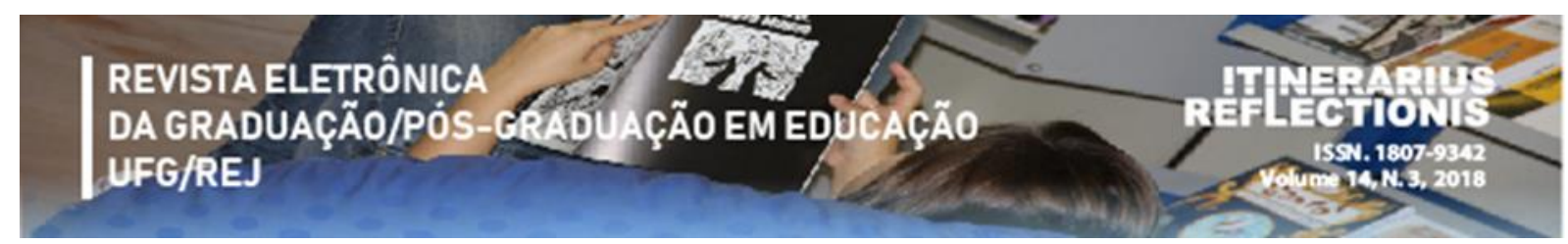

dificuldades encontradas para a oferta de cursos e turmas e três principais dificuldades foram levantadas, de caráter administrativo.

A primeira foi a dependência do trâmite operacional da UFG Regional Jataí em relação à UFG de Goiânia. Na instituição, todo o envio e retorno de processos, alimentação do sistema, sistema de gestão financeira e orçamentária (SISFOR) e emissão de diplomas é realizado pela UFG de Goiânia. O repasse de informações da PRPG (Pró-reitoria de PósGraduação) não ocorre de forma sistemática à Coordenação de Pós-graduação da UFG Regional Jataí (COPG) e quando há necessidade de um maior detalhamento da situação ou alguma dificuldade é encontrada, muitas vezes é necessário o deslocamento até Goiânia.

Assim, da digitação da proposta às notas e toda a tramitação de documentos dos alunos e dos cursos da Regional Jataí, em sua maioria absoluta, todo o trabalho era realizado pelos próprios coordenadores de curso até meados de 2016, quando a Secretaria de Pósgraduação (SPG) órgão orgânico da COPG tornou-se responsável por todos os processos. Entretanto, a secretaria geral, conta hoje, com apenas 4 (quatro) secretárias terceirizadas o que permite dizer que o número de técnicos administrativos é inexistente e insuficiente para a demanda do trabalho administrativo, fazendo com que parte deste trabalho ainda seja atribuído aos docentes coordenadores das respectivas pós-graduações.

De acordo com o MEC, a relação aluno equivalente/TAE (RAT) deve ser 15/1. Considerando os dados disponibilizados na página da Coordenação de Administração e Finanças (COAD) da Regional Jataí, esta conta com 7.388,60 aluno equivalente ou 3.100 alunos e, segundo os dados disponibilizados pelo Departamento Pessoal (DP) da Regional Goiânia são 112 Técnicos Administrativos em Educação (TAE), o que resulta na relação de 65,97 aluno equivalente/TAE ou 27,68 aluno/TAE, muito acima do proposto pelo MEC. Da mesma forma, se for avaliada a relação professor/TAE, a Regional Goiânia apresenta 0,95 professor para cada TAE enquanto que a Regional Jataí apresenta a relação de 3,2/1 indicando que parte das atividades administrativas que deveriam ser de atribuição de técnicos são desenvolvidas pelos professores.

A segunda dificuldade é o Regulamento Específico descrito na Resolução CEPEC N 1128 a qual regula os Cursos de Pós-graduação Lato Sensu da UFG e que exige, para abertura, tanto de novos cursos, como de novas turmas (não havendo distinção se o curso já teve turmas anteriores, se é de especialização ou residência) um novo projeto do curso proposto, com plano de trabalho, planilha financeira, declaração de execução de todos os 


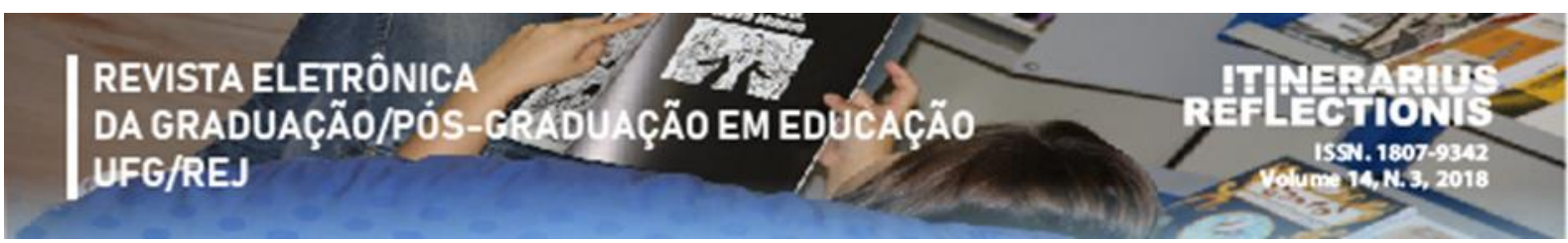

docentes, regulamento específico do curso, ata de reunião com a aprovação do novo curso e autorização do chefe da Unidade Acadêmica Especial para o funcionamento do mesmo.

Após o encaminhamento de toda a documentação à Pró-reitoria de Pósgraduação (PRPG), a Pró-reitoria de Administração e Finanças - PROAD analisa a proposta e encaminha à Câmara Regional de Pesquisa e Pós-graduação para deliberação com posterior envio ao CEPEC (Conselho de Ensino, Pesquisa, Extensão e Cultura), que emite a resolução de criação do curso, com a aprovação do respectivo regulamento, de forma que as atividades dos cursos de Pós-graduação Lato Sensu só podem ser iniciadas após a emissão da resolução.

Caso haja alguma alteração relativa às disciplinas, carga horária e quadro de docentes, a mesma deverá ser aprovada pelo Conselho Diretor da Unidade Acadêmica Especial ou do Órgão ao qual se vincula o curso, com posterior envio à PRPPG/PROAD para deliberação final já que o Regulamento Específico deve ser alterado e aprovado novamente. Essas alterações, se realizadas de forma mais simplificada, tornariam o processo mais dinâmico. Ou seja, se não houver alteração do Regulamento Específico do curso, a aberturas de novas turmas poderia ser automática, pelo menos em cursos que não cobram mensalidade.

O terceiro ponto, mas não menos importante foi, até recentemente, a falta de vinculação das informações no sistema atualmente utilizado pela universidade (SIGAA) para a cadastro das atividades curriculares. O SICAD (Sistema de Cadastro de Atividade Docente) não importava para o Relatório Anual de Atividades Docentes (RADOC) os dados das disciplinas ministradas do SIGAA. Esse problema também acontecia no SISCOREMU e no SISG, atual sistema utilizado pelos cursos de especialização fazendo com que a carga horária ministrada na especialização não fosse contabilizada para o professor, tornando-se um ônus para o professor.

A Residência Multiprofissional Médico Veterinária foi implementada na Regional Jataí em 2012 nas áreas de Clínica Médica, Clínica Cirúrgica e Anestesiologia de Animais de Companhia, de Reprodução Animal, de Patologia Animal, de Patologia Clínica e de Clínica e Cirurgia de Grandes Animais, ligadas à COREMU (Comissão de Residência Multiprofissional) da UFG, sediada na Regional Goiânia.

Atualmente, a Residência dispõe apenas da área de Clínica Médica, Clínica Cirúrgica e Anestesiologia de Animais de Companhia já que as demais áreas tiveram suas atividades descontinuadas a partir de 2013 , por recomendação de auditoria do MEC e do 


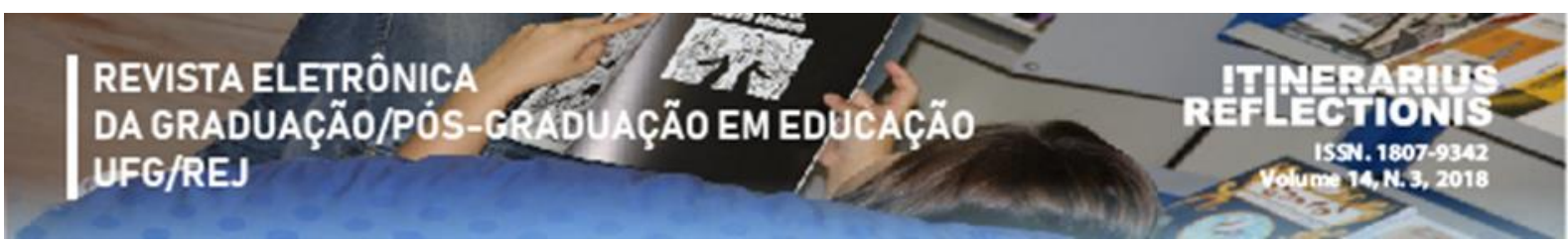

Conselho Federal de Medicina Veterinária, em função de denúncia no Ministério Público Federal, por parte dos próprios residentes.

$\mathrm{Na}$ auditoria foi constatado que as áreas não possuíam condições mínimas para atividades, devido à falta de estrutura física compatível, de corpo docente, de preceptores bem como de casuística para compor os programas. Observou-se que não havia hospital veterinário para grandes animais, bem como médicos veterinários servidores federais para atuarem como preceptores dos residentes nos laboratórios de patologia clínica, patologia animal e reprodução. Explica-se assim, a existência de apenas uma turma nas residências em Reprodução, Patologia Clínica, Patologia Animal e Clínica e Cirurgia de Grandes Animais (Tabela 1).

Na Tabela 2 são apresentados os cursos de especialização atualmente ativos na UFG Regional Jataí, com exceção da Residência em Clínica Médica, Clínica Cirúrgica e Anestesiologia em Animais de Companhia que tem entrada anual e processo seletivo realizado pelo Centro de Seleção, os demais cursos de pós-graduação Lato Sensu apresentados finalizaram o ingresso de alunos em 2017 e não abriram novas turmas em 2018.

Tabela 2 - Cursos de especialização atualmente em atividade na Regional Jataí, UFG, a respectiva Unidade Acadêmica Especial (UAE) e curso aos quais estão vinculados, bem como o número de docentes, número de vagas, duração do curso e tipo de anuidade (gratuita ou paga, com a descrição do valor)

\begin{tabular}{lccc}
\hline \multicolumn{1}{c}{ Especialização } & $\begin{array}{c}\text { Epidemiologia e } \\
\text { Saúde }\end{array}$ & Produção Florestal & $\begin{array}{c}\text { Políticas, Gestão e } \\
\text { Financiamento da } \\
\text { Educação }\end{array}$ \\
\hline Unidade Acadêmica & Ciências da Saúde & Ciências Agrárias & Educação \\
Especial Responsável & Medicina & Engenharia Florestal & Pedagogia \\
Curso & 7 & 9 & 26 \\
Docentes & 40 & 30 & 25 \\
Vagas & 384 horas & 360 horas & 404 horas \\
Duração & $(11$ meses $)$ & $(12$ meses $)$ & $(18$ meses $)$ \\
Anuidade & Gratuito & $\mathrm{R} \$ 3.100,00$ & Gratuito \\
\hline
\end{tabular}

Fonte: SISPG (2018).

O número de alunos titulados em cursos de pós-graduação Latu Sensu na Regional Jataí, até março de 2018, foi de 294 (Tabela 3) com média de $80 \%$ de titulação e permitindo inferir que os cursos geraram boa demanda e atingiram elevado percentual de titulação. Sendo que não houve titulados para o curso de Educação Física Escolar, que teve 


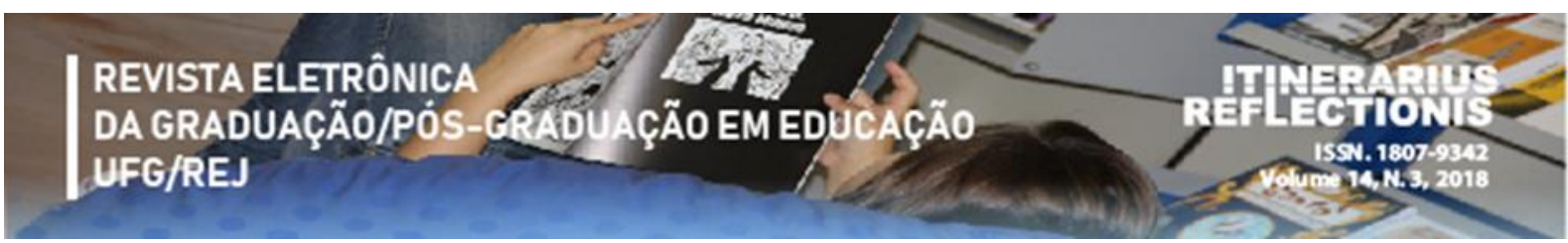

apenas uma inscrição e para o curso de Matemática, que não teve inscritos. Foi observado maior número de titulados na especialização em Educação Infantil, na qual foram ofertadas quatro turmas. Entretanto, a última turma titulada deu-se em 2011 e, até então, não foi feita nova oferta do curso.

Segundo Machado et al. (2016), a educação básica é uma área de alta demanda por especialização, que enseja maior profundidade e novas aprendizagens, onde os fundamentos e abordagens pedagógicas específicas do professor devem ser constantemente revistas e recicladas. Assim, a manutenção de cursos Lato Sensu como este certamente contribuiria para a melhorar a qualidade da educação básica na região e, por isso, de grande interesse institucional.

Apesar disso, os cursos com foco em Matemática foram os que apresentaram o menor percentual de titulação, talvez por ter não ter atingido o público alvo desejado.

O pequeno número de titulados nas turmas de residência (Tabela 3) deve-se a descontinuidade das turmas, como já discorrido anteriormente, e a oferta singular de vagas que ocorre nesta modalidade de Lato Sensu. As residência uni e multiprofissionais para atuação em áreas da saúde foram possibilitadas pelo MEC a partir de 2011 e a oferta de vagas depende de aprovação prévia pelo órgão, que fornece uma bolsa de $\mathrm{R} \$ 3.330,43$ (Três mil trezentos e trinta reais e quarenta e três centavos - julho de 2018) mensais para cada residente. O número de vagas a ser ofertado pela instituição proponente também deve, obrigatoriamente, considerar a casuística do local e a presença de preceptores durante todas as atividades teórico-práticas. Desta forma, atualmente, são abertas cinco vagas por ano na área de clínica médica, cirúrgica e anestesiologia em animais de companhia, no Hospital Veterinário da Regional Jataí. Como o curso é de dois anos, mas a entrada de alunos é anual, o Hospital Veterinário possui dez residentes. Dentre os ingressantes, houve apenas duas desistências até 2017, por motivos pessoais.

As residências apresentam estrutura diferente dos demais cursos de Pósgraduação Lato Sensu uma vez que requerem Projeto Pedagógico, além do Regulamento Específico e, tem corpo profissional de apoio constituído de coordenador, preceptores, supervisores, tutores/orientadores, professores e residentes de modo a cumprir o total de carga horária téorico-prática de 5.760 horas em dois anos em 60 horas de atividades semanais (BRASIL, 2014). 
REVISTA ELETRÔNICA

DA GRADUAÇÃO/PÓS-CRADUAÇÃO EM EDÜCACĈ̃O

UFG/REJ

Em 2017 a decisão do Tribunal Regional Federal da 1ª Região (TRF1) de proibir a UFG de cobrar mensalidade por um curso de especialização em direito constitucional fez com que alguns cursos adiassem a abertura de novas turmas. Em 25 de abril de 2017 o Supremo Tribunal Federal (STF) autorizou o recurso da UFG contra a decisão do TRF1, permitindo às universidades públicas cobrar taxas e mensalidades pela oferta de cursos de pós-graduação Lato Sensu.

Tabela 3 - Número de alunos titulados por curso de pós-graduação latu sensu na Regional Jataí, UFG, até março de 2018

\begin{tabular}{|c|c|c|}
\hline Curso & $\begin{array}{c}\text { Número de } \\
\text { Alunos } \\
\text { Titulados }\end{array}$ & $\begin{array}{c}\text { Titulados } \\
(\%)\end{array}$ \\
\hline $\begin{array}{l}\text { Avaliação e Prescrição de Exercícios Físicos para Populações } \\
\text { Especiais }\end{array}$ & 21 & 80 \\
\hline Biologia & 24 & 80 \\
\hline Educação Física Escolar & - & - \\
\hline Educação Infantil & 67 & 87 \\
\hline Epidemiologia e Saúde & 32 & 100 \\
\hline Gestão de Pessoas nas Organizações Públicas & 14 & 64 \\
\hline História Cultural: Narrativas e Linguagens & 10 & 43 \\
\hline $\begin{array}{l}\text { Linguística Aplicada ao Ensino de Língua Materna e } \\
\text { Estrangeira (Inglês) }\end{array}$ & 13 & 100 \\
\hline Literatura e Língua Portuguesa & 31 & 100 \\
\hline Matemática & - & - \\
\hline Matemática Aplicada & 8 & 38 \\
\hline Matemática para Professores de Ensino Fundamental e Médio & 4 & 21 \\
\hline Meio Ambiente: Educação e Gestão Ambiental & 20 & 55 \\
\hline Políticas, Gestão e Financiamento da Educação & 8 & 87 \\
\hline Produção de Suinos & 14 & 83 \\
\hline Produção Florestal & 7 & 78 \\
\hline Residência Médico Veterinária em Reprodução Animal & 2 & 100 \\
\hline Residência Médico Veterinária em Patologia Animal & 1 & 100 \\
\hline Residência Médico Veterinária em Patologia Clínica & 1 & 100 \\
\hline $\begin{array}{l}\text { Residência Médico Veterinária em Clínica e Cirurgia de } \\
\text { Grandes Animais }\end{array}$ & 1 & 100 \\
\hline $\begin{array}{l}\text { Residência Médico Veterinária em Clínica Médica, Clínica } \\
\text { Cirúrgica e Anestesiologia de Animais de Companhia }\end{array}$ & 16 & 100 \\
\hline Total geral/Média & 294 & 80 \\
\hline
\end{tabular}

O STF entendeu que os mesmos têm caráter de especialização e dão direito a um certificado e não a um diploma, como no caso de mestrados e doutorados. O julgamento 


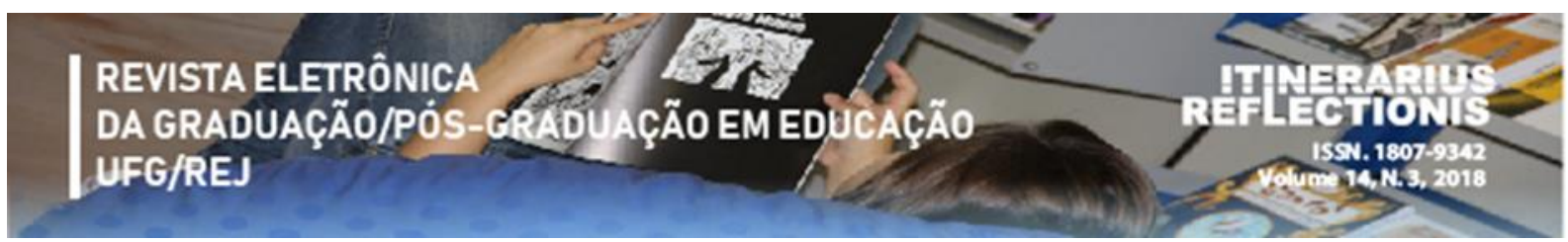

foi válido para todo o sistema público do ensino superior, em que havia 51 processos judiciais suspensos, de várias universidades brasileiras, aguardando o posicionamento do STF.

Entretanto, apesar do posicionamento do STF, o prazo máximo para abertura de novas turmas para o segundo semestre de 2017 estava muito próximo, impossibilitando a adequação dos projetos para abertura de novas turmas. Posteriormente, não foi observado interesse na abertura de novos cursos

Outra dificuldade é a necessidade de liberação de usuário pela PRPG, que autoriza o acesso aos dados do curso, pelo fornecimento de uma senha única, apenas ao coordenador, sendo que as informações acabavam ficando descentralizadas e desconectadas. No ano de 2018 a Coordenação de Pós-graduação da Regional Jataí (COPG) conseguiu a autorização para acessar todos os cursos de especialização e centralizar a operacionalização dos dados cadastrais de alunos, bem como notas e presenças para a emissão do histórico e a titulação do aluno.

Entretanto, assim que a COPG teve acesso a todos os cursos, constatou a falta de informações cadastradas, como notas e frequências dos alunos, apesar de a Resolução exigir que os alunos sejam matriculados no SISPG no prazo máximo de trinta (30) dias após o início do curso, não sendo permitida a inclusão de novos alunos após este período que no em até sessenta (60) dias após o término do curso, a Coordenação deve concluir o preenchimento dos dados acadêmicos dos alunos no SISPG e encaminhar à PRPPG a relação dos alunos concluintes que cumpriram todos os requisitos estabelecidos neste Regulamento e nas normas específicas do curso, tornando clara a falta de comunicação entre a PRPG e os coordenadores dos cursos e delatando a dificuldade dos coordenadores inserirem no sistema e enviarem as informações para a PRPG mantendo-as atualizadas no órgão responsável pela emissão dos certificados. Até 2015 apenas a PRPG e o Coordenador do Curso tinham acesso aos cursos no SISPG e, além disso, todos os documentos eram encaminhados fisicamente, via protocolo, para a Regional Goiânia. Alguns documentos foram perdidos antes do estabelecimento do protocolo na Regional Jataí, além de haver o fator tempo de deslocamento já que os documentos percorriam o percurso coordenação do curso-protocolo-transporte-protocoloPRPG e atribuição ao responsável.

\section{PERSPECTIVAS FUTURAS}




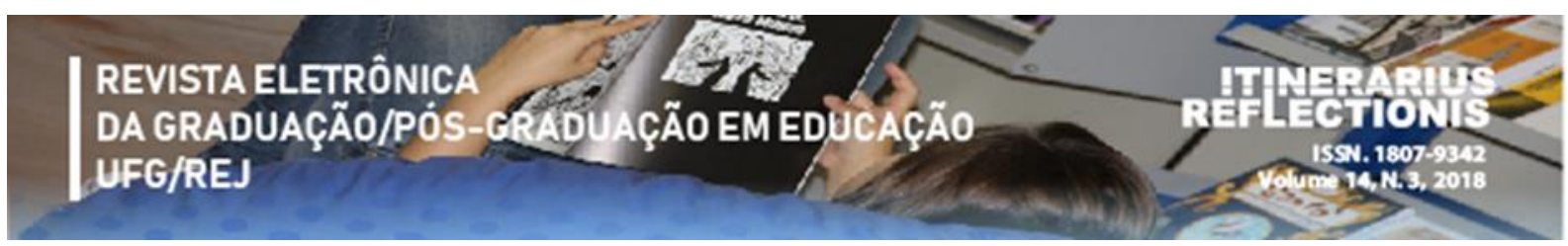

Devido às dificuldades listadas, após a autorização de acesso a todos os cursos de especialização e residência da UFG Regional Jataí, a primeira atitude da COPG foi centralizar as informações na Secretaria da Pós-graduação, solicitando e passando a administrar todos os dados dos cursos, cadastro de alunos, matrícula da residência veterinária e todos os demais trâmites administrativos.

O próximo passo da COPG será o de recuperar os dados dos cursos para lançamento no SISPG, para a atualização das informações. Concomitantemente, com a criação da Universidade Federal de Jataí, será revisto o processo de abertura de novos cursos de especialização, especialmente de novas turmas, de cursos pré-existentes.

Também será efetivada a melhor comunicação entre coordenadores e professores, com todas as informações e formulários pertinentes no sítio do Lato Sensu, além da realização de reuniões periódicas com os coordenadores dos cursos.

Como perspectiva, tem-se ainda o fato de que o curso de graduação em Medicina que iniciou suas atividades em agosto de 2014 na UFG Regional Jataí e tem previsão de formar a primeira turma em 2020, já está estruturando a Residência Médica. No início de 2018 foi emitida uma portaria estabelecendo a COREME (Comissão de Residência Médica) própria que, atualmente, está preparando a eleição dos médicos que a comporão.

Já existe um projeto de Residência Médica escrito na área de Medicina da Família e, após o estabelecimento da COREME, o projeto será enviado ao MEC solicitando a abertura do curso. Assim, existe a perspectiva da abertura do processo seletivo para residência médica na Regional Jataí brevemente.

\section{CONCLUSÕES}

A UFG Regional Jataí ofertou e tem ofertado pequeno número de cursos e turmas de Pós-graduação Lato Sensu, apresentando grande descontinuidade e demonstrando grande desinteresse por parte dos coordenadores, professores e alunos.

Por isso, e considerando que a Regional possui capacidade para ofertar cursos de pós-graduação Lato Sensu em diversas áreas, deve-se desenvolver um trabalho de estímulo aos atores do processo, porém, sem focar demandas específicas e pontuais que não favoreçam a continuidade dos mesmos.

Além disso, hoje o sistema contabiliza plenamente a carga horária ministrada no Lato Sensu no relatório de atividades docente e a centralização de informações na Secretaria 


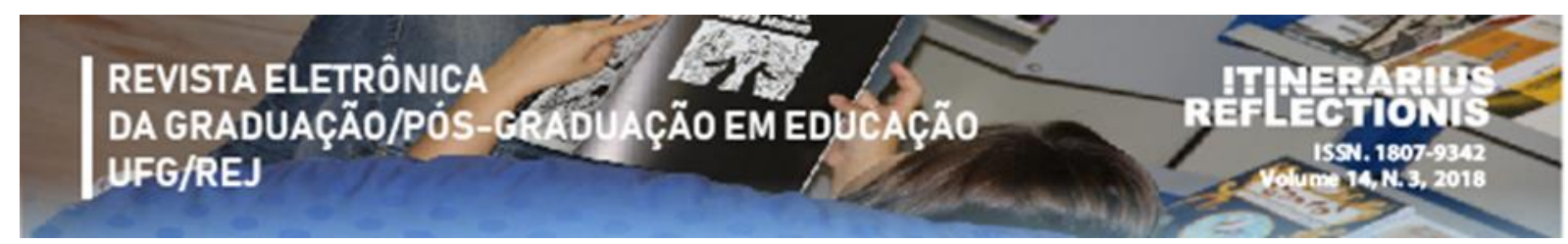

de Pós-graduação pode proporcionar suporte ao processo, favorecendo o fluxo de informações, o esclarecimento de dúvidas e situações, o que, se espera, estimule a criação de novas turmas e cursos demandados a partir de levantamentos realizados por área, na região, afim de direcionar à oferta de cursos com turmas contínuas.

\section{REFERÊNCIAS BIBLIOGRÁFICAS}

BRASIL. Resolução ${ }^{\circ}$ 5, de 7 de novembro de 2014. Dispõe sobre a duração e a carga horária dos programas de Residência em Área Profissional da Saúde nas modalidades multiprofissional e uniprofissional e sobre a avaliação e a frequência dos profissionais da saúde residentes. Diário Oficial da União. Brasília, DF, 10 de nov. 2014. Seção 1, p.34. Disponível em:

http://pesquisa.in.gov.br/imprensa/jsp/visualiza/index.jsp?jornal=1\&pagina=34\&data=10/11/2 014. Acesso em: 06 jul. 2018.

FONSECA, M.; FONSECA, D.M. da. A gestão acadêmica da pós-graduação Lato Sensu: o papel do coordenador para a qualidade dos cursos. Educação e Pesquisa [on line], v. 42, 2016. Disponível em: 〈http://www.redalyc.org/articulo.oa?id=29844947011> . Acesso em: 19 de maio 2018.

IBGE - Instituto Brasileiro de Geografia e Estatística. Cidades. Panorama de Goiânia. Disponível em: https://cidades.ibge.gov.br/brasil/go/goiania/panorama. Acesso em 6 jul. 2018.

LDB n ${ }^{\circ}$ 9.394/1996. Estabelece as diretrizes e bases da educação nacional. LEI N 9.394, DE 20 DE DEZEMBRO DE 1996. Disponível em: <http://www2.camara.leg.br/legin/fed/lei/1996/lei-9394-20-dezembro-1996-362578publicacaooriginal-1-pl.html>. Acesso em: 21 de maio de 2018.

MACHADO, M.A.C.; BEZERRA, A.A.C.; NOBRE, L.M.; SANTOS. K.M.L.; SILVA, S.M.S.M.T. Política de formação docente: a Universidade Aberta do Brasil e a Formação Inicial e Continuada Docente para a Educação de Jovens e Adultos. Investigação Qualitativa em Educação. Volume 1, 2016. Disponível em:

$<$ http://proceedings.ciaiq.org/index.php/ciaiq2016/article/view/1075/1048 >. Acesso em: 21 de maio 2018.

NOTA TÉCNICA no 388/2013. Dúvidas mais frequentes sobre regulação e supervisão da Educação Superior - Pós-graduação Lato Sensu. Nota Técnica ${ }^{\circ}$

388/2013/CGLNRS/DPR/SERES/MEC, DE 21 DE JUNHO DE 2013. Disponível em: <http://www.abmes.tv.br/legislacoes/detalhe/1452/nota-tecnica-n-388-2013-cglnrs-dprseres-mec $>$. Acesso em: 21 de maio 2018.

PARECER Nº 977/65. Definição dos cursos de pós-graduação. PARECER No 977/65, CESu, Publicado em 03/12/1965. Disponível em: 
REVISTA ELETRÔNICA

DA GRADUAÇÃO/PÓS-CRADUAÇÃO EM EDÜCACĈ̃O

UFG/REJ

$<$ https://www.capes.gov.br/images/stories/download/avaliacao/avaliacao-n/Parecer-9771965.pdf >. Acesso em: 21 de maio 2018.

PRPG - Pró-reitoria de Pós-graduação. Cursos de Pós-graduação Lato sensu -

Especialização. Goiânia: UFG, 2018. Disponível em: https://prpg.ufg.br/p/6663-cursos-depos-graduacao-lato-sensu-especializacao. Acesso em: 6 jul. 2018.

RESOLUÇÃO - CEPEC No 1128. Aprova o Regulamento Geral dos Cursos de PósGraduação LATO SENSU da UFG. Resolução - CEPEC No 1128, revoga a Resolução CEPEC No 742. Disponível em:

<https://prpg.ufg.br/up/85/o/res_1128_2012.pdf>. Acesso em: 21 de maio 2018.

SISPG - SISTEMA DE PÓS-GRADUAÇÃO. Módulos: Lato Sensu e Residência Multiprofissional. Goiânia: UFG, 2003.

UFG - Universidade Federal de Goiás. A Regional Jataí em números. Jataí: REG/UFG, 2015. Disponível em: https://www.jatai.ufg.br/p/1892-a-regional-jatai-em-numeros. Acesso em 6 jul. 2018.

USP - Universidade de São Paulo. Anuário estatístico. São Paulo, 2018. Disponível em: https://uspdigital.usp.br/anuario/AnuarioControle. Acesso em: 6 jul. 2018. 